\title{
RNAi-mediated RPL34 knockdown suppresses the growth of human gastric cancer cells
}

\author{
HUI LIU ${ }^{1}$, SHAOHUA LIANG ${ }^{1}$, XI YANG ${ }^{1}$, ZHAONING JI $^{2}$, WENYING ZHAO ${ }^{2}$, XIAOBING YE ${ }^{2}$ and JING RUI ${ }^{2}$ \\ ${ }^{1}$ Department of Oncology, Wannan Medical College, Wuhu, Anhui 241001; ${ }^{2}$ Department of Medical Oncology, \\ Yijishan Hospital of Wannan Medical College, Wuhu, Anhui 241001, P.R. China
}

Received June 15, 2015; Accepted August 7, 2015

DOI: $10.3892 /$ or.2015.4219

\begin{abstract}
An increasing body of evidence suggests that ribosomal proteins may have ribosome-independent functions and may be involved in various physiological and pathological processes. To examine the role of ribosomal protein L34 (RPL34) in cancer transformation, we assessed its expression in gastric cancer cell lines and found it highly expressed. We further used lentivirus-mediated small interfering RNAs (siRNAs) to knockdown RPL34 expression in the human gastric cancer cell line SGC-7901. RNA interference (RNAi)mediated inhibition of RPL34 expression in SGC-7901 cells significantly suppressed cell proliferation, increased apoptosis and arrested cells in the $\mathrm{S}$ phase. The results of the present study suggest that RPL34 plays a critical role in cell proliferation, cell cycle distribution and apoptosis of human malignant gastric cells.
\end{abstract}

\section{Introduction}

Gastric cancer (GC) is the second most common cancer in Asia and particularly in Eastern Asia $(1,2)$, and is still the third most frequent cause of cancer-related deaths, after lung and liver cancer in males and breast and lung cancer in females (3-5). The survival of patients with GC has improved along with marked advances in diagnostic and therapeutic modalities. However, the high rate of relapse and metastasis of GC results in poor long-term survival $(6,7)$. Thus, there is an urgent need to develop new treatment strategies for GC.

In eukaryotes, ribosomes contain $\sim 80$ different ribosomal proteins (RPs). Evidence has demonstrated that appropriate regulation of RP genes is crucial for normal ribosome biosynthesis (8), and their activity is required for the growth and maintenance of all types of cells $(9,10)$. Loss of normal regulation of RPs has been associated with pathological conditions, such as neoplasia (11) and Turner syndrome (12).

Correspondence to: Dr Jing Rui, Department of Medical Oncology, Yijishan Hospital of Wannan Medical College, 2 Zheshan Western Road, Wuhu, Anhui 241000, P.R. China

E-mail: ruijing1956@sina.com

Key words: RPL34, SGC-7901, proliferation, apoptosis
The gene encoding ribosomal protein L34 (RPL34) has been identified in the human $(13,14)$, mouse $(15)$ and rat $(13,16,17)$. However, no functional information has been available to date for RPL34 in human cancer and GC in particular.

In the present study, we confirmed that RPL34 is highly expressed in GC cell lines. Subsequently, we employed the lentivirus-delivered small interfering RNA (siRNA) technique to examine the effect of RPL34 knockdown on human GC cell growth in vitro.

\section{Materials and methods}

Cell lines. Human gastric adenocarcinoma cell lines SGC-7901, MGC80-3, BGC-823 and MKN-45 and human renal epithelial 293T cells were purchased from the Shanghai Cell Bank (Shanghai, China). Cell lines were cultured in RPMI-1640 medium, supplemented with $10 \%$ fetal bovine serum (FBS), sodium pyruvate, non-essential amino acids, L-glutamine, a 2-fold vitamin solution (all from Gibco ${ }^{\circledR}$, Shanghai, China), $100 \mathrm{U} / \mathrm{ml}$ penicillin and $0.1 \mathrm{mg} / \mathrm{ml}$ streptomycin (Sangon Co., Ltd., Shanghai, China) at $37^{\circ} \mathrm{C}$ in a $5 \% \mathrm{CO}_{2}$ incubator.

Quantitative RT-PCR. Total RNA from the 4 cell lines, SGC-7901, MGC80-3, BGC-823 and MKN-45, was extracted using the TRIzol reagent (Invitrogen, Shanghai, China), according to the manufacturer's instructions and was then used for RT reaction. Briefly, $2 \mu \mathrm{g}$ of total RNA from each sample was reverse transcribed to single-stranded cDNA. One microliter of cDNA was used as a template for the following PCR. The primers used were as follows: for RPL34 forward, 5'-GTT TGA CAT ACC GAC GTA GGC-3' and reverse, 5'-GCA CAC ATG GAA CCA CCA TAG-3'; and for GAPDH forward, 5'-TGA CTT CAA CAG CGA CAC CCA-3' and 5'-CAC CCT GTT GCT GTA GCC AAA-3'. The quantitative RT-PCR comprised an initial denaturation at $95^{\circ} \mathrm{C}$ for $15 \mathrm{sec}$, then 45 cycles at $95^{\circ} \mathrm{C}$ for $5 \mathrm{sec}$ and $60^{\circ} \mathrm{C}$ for $30 \mathrm{sec}$. The PCR products of RPL34 and GAPDH were 241 and $121 \mathrm{bp}$, respectively. All samples were examined in triplicates.

Recombinant lentiviral vector production and cell infection. The complementary DNA sequence (CCTAAAGTTCTTA TGAGAT) of RPL34 was designed from the full-length RPL34 sequence (GenBank no. CR542242.1) by GeneChem Co. Ltd. (Shanghai, China). After testing knockdown efficiencies, the 
stem-loop oligonucleotides were synthesized and inserted into the lentivirus-based pGCSIL-GFP (GeneChem Co. Ltd.) with AgeI/EcoRI sites. Lentivirus particles were prepared as previously described (18).

For lentivirus infection, SGC-7901 cells were cultured into 6-well plates and then the RPL34-siRNA-lentivirus or negative control (NC) lentivirus was added according to a multiplicity of infection (MOI). After $72 \mathrm{~h}$ of infection, the cells were observed under a fluorescence microscope (MicroPublisher 3.3RTV; Olympus, Tokyo, Japan). After $120 \mathrm{~h}$ of infection, the cells were harvested to determine knockdown efficiency by quantitative RT-PCR.

Western blot analysis. The cells were collected and lysed using ice-cold lysis buffer (50 mM Tris, $\mathrm{pH} 7.4,150 \mathrm{mM} \mathrm{NaCl}, 1 \%$ SDS, $1 \mathrm{mM}$ EDTA, $1 \% \mathrm{NP}-40)$ containing $1 \mathrm{mM}$ protein inhibitor and $1 \mathrm{mM}$ PMSF, for $30 \mathrm{~min}$ on ice. The lysates were centrifuged at $10,000 \mathrm{x} \mathrm{g}$ at $4^{\circ} \mathrm{C}$ for $10 \mathrm{~min}$ and the supernatants were collected. Protein concentration was measured using the BCA protein assay (HyClone-Pierce, Rockford, IL, USA). Equal amounts of total protein of each treatment were separated using 12.5\% SDS-PAGE according to Laemmli's method (19), and were then transferred onto PVDF membranes. Membranes were incubated with mouse anti-FLAG or anti-GAPDH antibodies (Santa Cruz Biotechnology, Santa Cruz, CA, USA). Western blotting was developed using horseradish peroxidase-conjugated goat anti-mouse IgG (Santa Cruz Biotechnology) and was detected by enhanced chemiluminescence (ECL) reagent (ECL-Plus/Kit; Amersham, Piscataway, NJ, USA).

Cell growth assay. Cell growth was measured using multiparametric high-content screening (HCS) similarly to and as described by Zhou et al (20) with some modifications. Briefly, SGC-7901 cells at the logarithmic phase after being infected with either the NC lentivirus or RPL34-siRNA lentivirus were seeded at 2,000 cells/well into 96-well plates; the cells were then incubated at $37^{\circ} \mathrm{C}$ with $5 \% \mathrm{CO}_{2}$ for 5 days. The cells in the plates were counted using the Cellomics ArrayScan ${ }^{\mathrm{TM}}$ VT1 HCS automated reader (Cellomics, Inc., Pittsburgh, PA, USA) for each day's analysis. In each well, at least 800 cells were analyzed. Each experiment was performed in triplicates.

Analysis of cell cycle distribution and apoptosis. Flow cytometry (FCM) analysis was used to determine the cell cycle distribution or detect apoptosis and was performed as previously described (21). Briefly, SGC-7901 cells were infected with RPL34-siRNA or NC plasmids and incubated at $37^{\circ} \mathrm{C}$ for $1,2,3,4$ or 5 days. At the indicated time point, adherent cells were collected, washed twice with ice-cold phosphate-buffered saline (PBS), fixed with $\sim 0.5 \mathrm{ml}$ of ice-cold $70 \%$ ethanol at $4^{\circ} \mathrm{C}$ for $1 \mathrm{~h}$, and stained with propidium iodide (PI; $50 \mu \mathrm{g} / \mathrm{ml}$, Sigma-Aldrich ${ }^{\circledR}$ Co. LLC., St. Louis, MO, USA) in the presence of RNase A $\left(100 \mu \mathrm{g} / \mathrm{ml}\right.$; Fermentas ${ }^{\circledR}$, Shanghai, China). The suspension was filtered through a 300-mesh, and the DNA content of the stained nuclei was analyzed for the cell cycle phase by BD FACSCalibur flow cytometer (BD Biosciences, San Diego, CA, USA). Each experiment was performed in triplicates.

Cell apoptosis was assayed by staining with Annexin V-APC (eBioscience, San Diego, CA, USA) and detected by FCM.

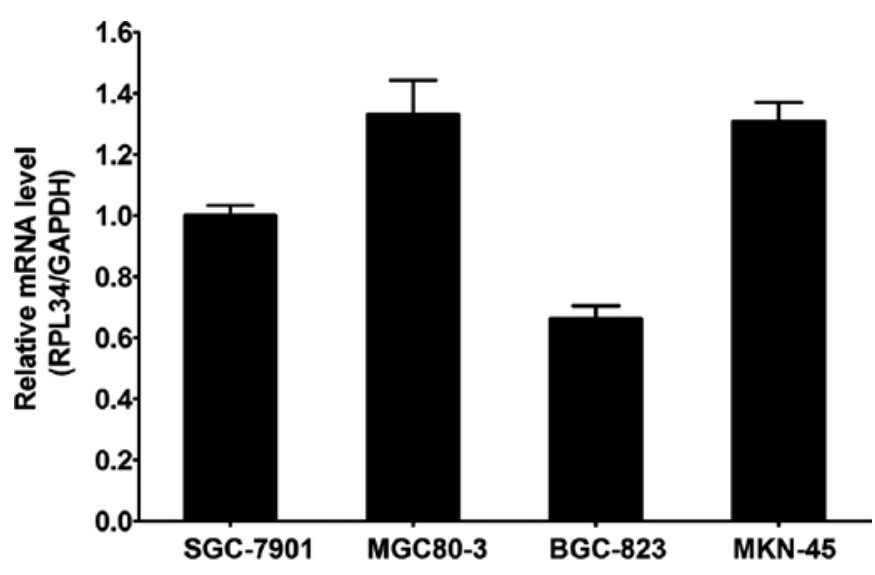

Figure 1. RPL34 mRNA levels in four gastric cancer cell lines. Expression of RPL34 mRNA was measured by RT-PCR in the indicated cell lines. A constitutively expressed $G A P D H$ gene was used as an internal control.

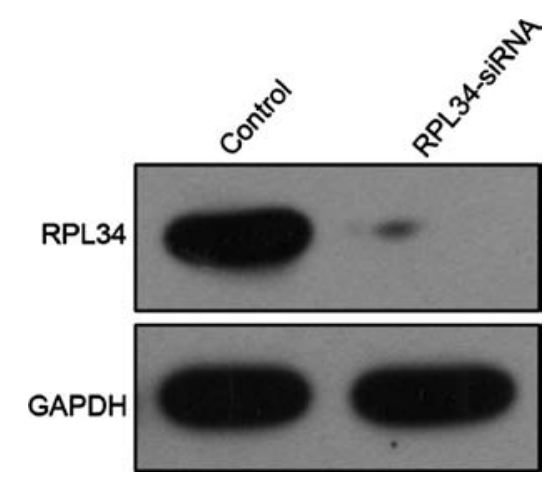

Figure 2. Knockdown of RPL34 protein expression in 293T cells. RPL34 protein expression was analyzed by western blotting in control-transfected (NC) and RPL34-siRNA-transfected 293T cells. GAPDH was used as a loading control.

For analysis of apoptosis, SGC-7901 cells were cultured into 6-well plates. After $48 \mathrm{~h}$ of transfection with RPL34-siRNA or NC plasmids, the cells were collected and washed twice with ice-cold PBS. The cell concentrations were adjusted to $1 \times 10^{6} / \mathrm{ml}$ with $1 \mathrm{X}$ staining buffer. One-hundred microliters of cell suspension was stained with $5 \mu \mathrm{l}$ Annexin V-APC at room temperature in the dark for $15 \mathrm{~min}$. Cells were analyzed using FCM within $1 \mathrm{~h}$. All experiments were performed in triplicates.

Statistical analysis. The Student's t-test was used for raw data analysis. Statistical analysis was performed using SPSS for Windows version 16.0 (SPSS, Inc., Chicago, IL, USA). The statistical data for each group were presented as the mean \pm SD. A value of $\mathrm{p}<0.05$ was accepted as statistically significant.

\section{Results}

RPL34 mRNA detection in four GC cell lines. The expression of RPL34 mRNA was assessed in gastric cancer cell lines SGC-7901, MGC80-3, BGC-823 and MKN-45 by RT-PCR. The results showed that RPL34 mRNA was expressed in all four cell lines (Fig. 1). 

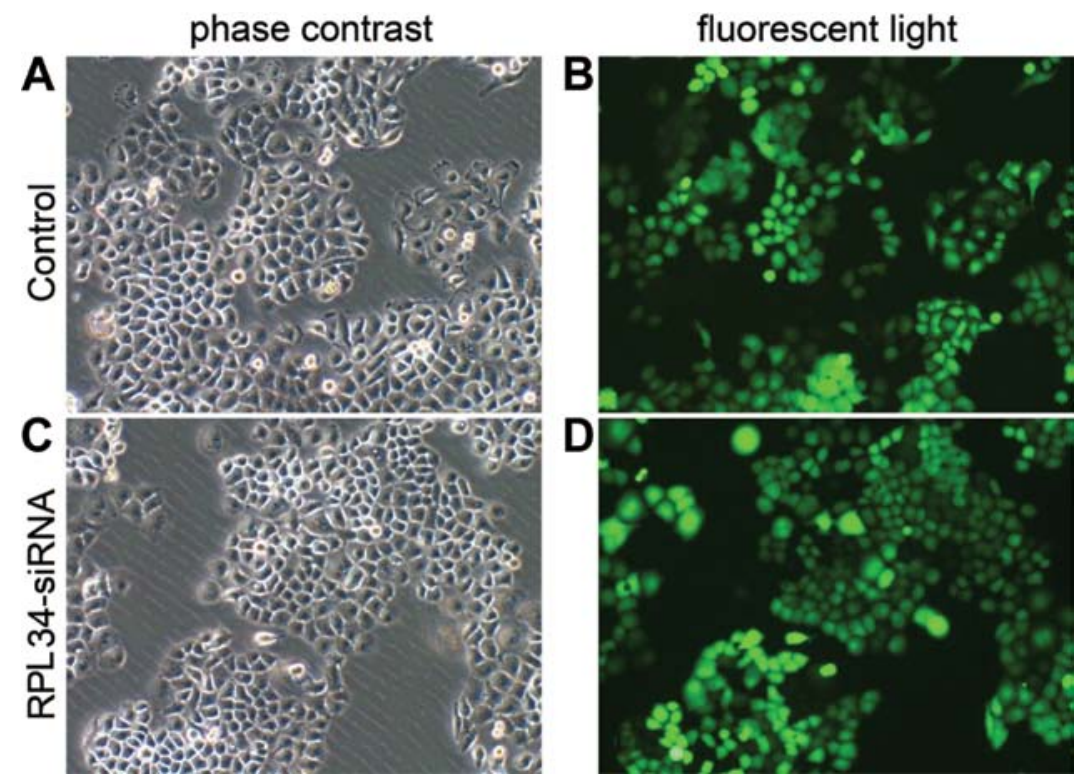

Figure 3. Assessing efficiency of infection of SGC-7901 cells with RPL34-siRNA or NC lentivirus vectors. SGC-7901 cells were infected with RPL34-siRNA or NC lentivirus and examined by fluorescent microscopy and light microscopy at day 3 post infection. Note that most of the cells express GFP. Magnification, x100. Representative images of the cultures are shown.

Knockdown efficiency determined by western blot analysis. Human embryonic kidney $293 \mathrm{~T}$ cells were infected with RPL34-siRNA lentivirus or NC lentivirus. As shown in Fig. 2, RPL34 protein expression was detected by western blotting in these cells, but was greatly reduced in the RPL34-siRNA infected cultures, indicating effective knockdown of the target sequence.

Lentivirus-mediated knockdown of RPL34 in the human GC cell line SGC-7901. To explore the role of RPL34, we knocked down RPL34 in the SGC-7901 cell line. As shown in Fig. 3, by day 3 post infection, the proportion of infected cells was $>80 \%$ for both the RPL34-siRNA and NC lentivirus. RPL34 mRNA levels were assessed by real-time PCR at day 5 post infection with either the RPL34-siRNA or NC lentivirus. RPL34-siRNA lentivirus-infected cultures had significantly lower levels of RPL34 mRNA compared to levels in the cultures infected with the NC lentivirus (Fig. 4).

Knockdown of RPL34 in SGC-7901 cells inhibits cell proliferation. To examine the effect of RPL34 on cell growth, SGC-7901 cells expressing either the RPL34-siRNA or NC lentivirus were seeded into 96 -well plates and analyzed by Cellomics every day for 5 days. As illustrated in Fig. 5A and confirmed by quantification in Fig. 5B, control-transfected cells greatly expanded over the 5 days of the experiment, while the number of RPL34-siRNA-transfected cells did not change. The cell growth rate was defined as: Cell count at 9 days/cell count at first day, where $n=2,3,4$ and 5 (Fig. 5B). The results of the present study showed that RPL34 knockdown significantly inhibited proliferation of the SGC-7901 cells.

Knockdown of RPL34 in SGC-7901 cells leads to cell cycle arrest. To determine whether RPL34 is necessary for cell cycle progression in SGC-7901 cells, we assessed the cell cycle phases in SGC-7901 cells by flow cytometry (Fig. 6A). The

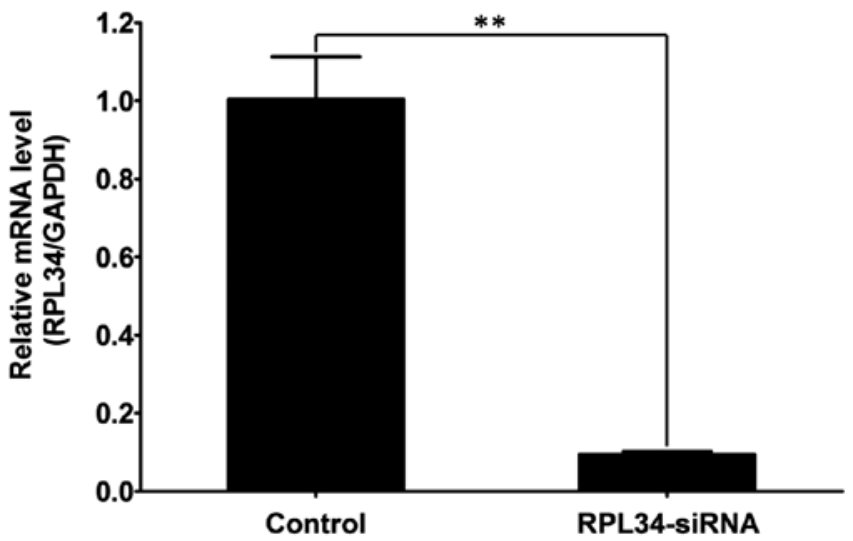

Figure 4. Confirmation of RPL34 knockdown in SGC-7901 cells. SGC7901 cells were infected with RPL34-siRNA or NC lentivirus and RPL34 mRNA levels were analyzed using real-time PCR at day 5 post infection. Note that the RPL34 mRNA level decreased significantly after RPL34 knockdown. ${ }^{* *} \mathrm{p}<0.01$

NC group displayed the following distribution: $\left(\mathrm{G}_{0} / \mathrm{G}_{1}\right.$ phase, $52.02 \pm 0.87 \%$; $S$ phase, $41.95 \pm 0.98 \%$; and $\mathrm{G}_{2} / \mathrm{M}$ phase, $6.03 \pm 1.40 \%$ ), and the RPL34-siRNA group displayed the following: $\left(\mathrm{G}_{0} / \mathrm{G}_{1}\right.$ phase, $67.65 \pm 1.00 \%$; $\mathrm{S}$ phase, $25.02 \pm 0.91 \%$; and $\mathrm{G}_{2} / \mathrm{M}$ phase, $7.33 \pm 0.14 \%$ ). As shown in Fig. $6 \mathrm{~B}$, compared to the control cultures, RPL34-siRNA lentivirus cultures displayed a significant decrease in the percentage of cells in the $S$ phase $(p<0.01)$ and an increase in the percentage of cells in the $G_{2} / M$ phase $(p<0.01)$. Taken together, these data suggest that RPL34 regulates cell growth and blocks cell cycle progression in the $\mathrm{G}_{2} / \mathrm{M}$ phase.

Knockdown of RPL34 in SGC-7901 cells increases cell apoptosis. To test whether RPL34 expression affects apoptosis in GC cells, we knocked down RPL34 in SGC-7901 cells. Cell apoptosis was determined by Annexin $\mathrm{V}$ staining followed 
A

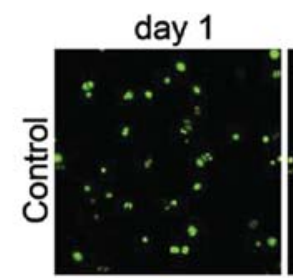

day 2

day 3

day 4
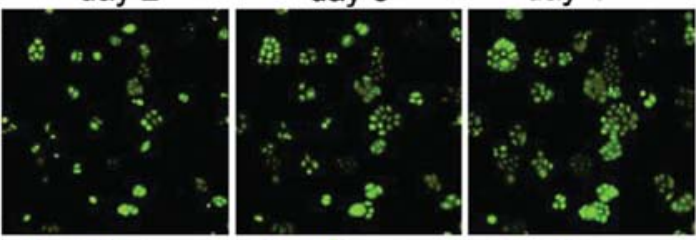

day 5
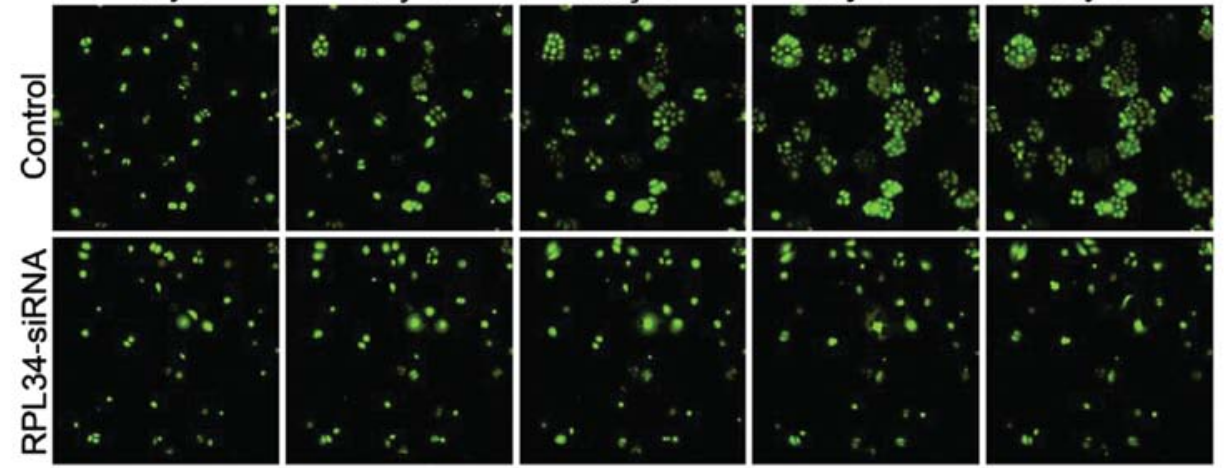

B
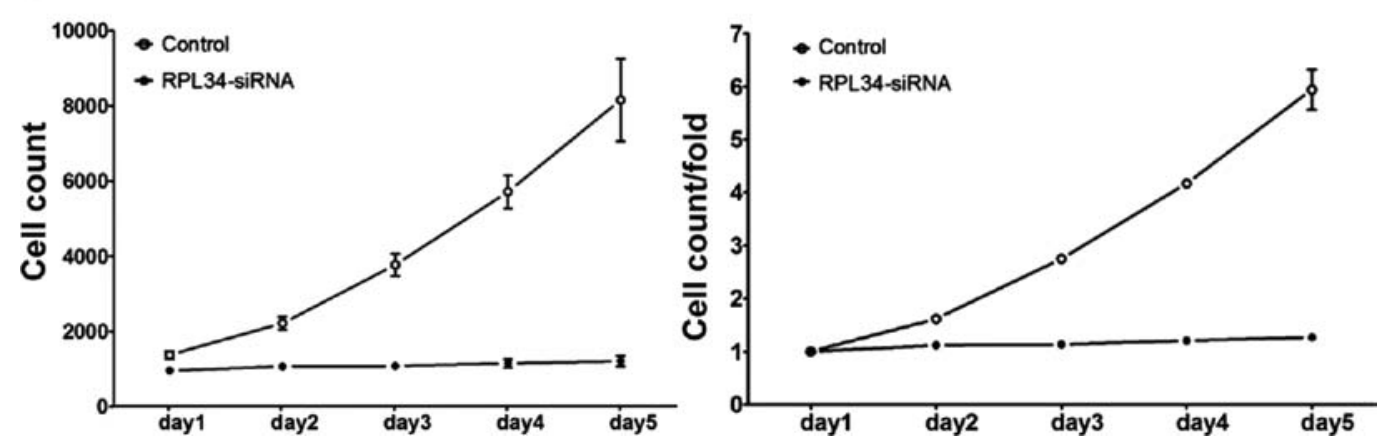

Figure 5. Effect of RPL34 knockdown on SGC-7901 cell growth. (A) Cells were infected with the control or RPL34-siRNA lentivirus and high content cell imaging was applied every day as indicated to acquire raw images (unprocessed by software algorithm) of cell growth. (B) Cells were seeded into 96-well plates and infected with the control or RPL34-siRNA lentivirus and cell growth was assayed every day for 5 days (NC vs. RPL34-siRNA, p<0.05).
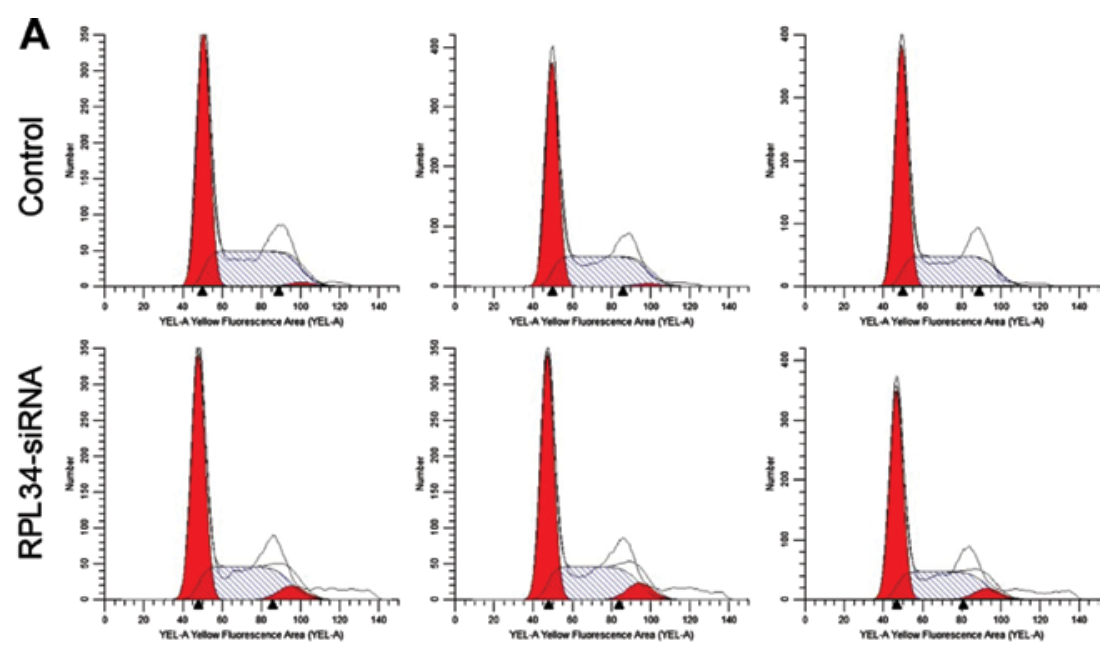

B

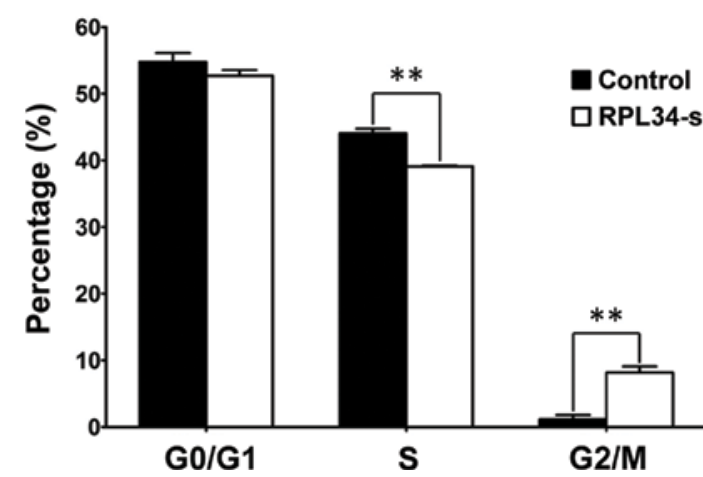

Figure 6. RPL34 knockdown leads to cell cycle arrest. (A) Cell cycle of SGC-7901 cells was analyzed by flow cytometry. Each group is shown in triplicates. Note S-phase arrest in the knockdown sample. (B) Cell cycle phases determined by flow cytometry. Compared with NC, RPL34-siRNA cultures showed a

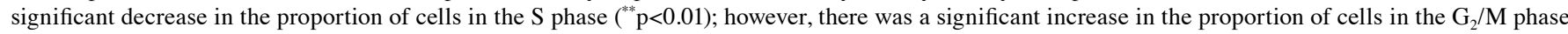
$\left({ }^{*} \mathrm{p}<0.01\right)$, compared with the NC group. 


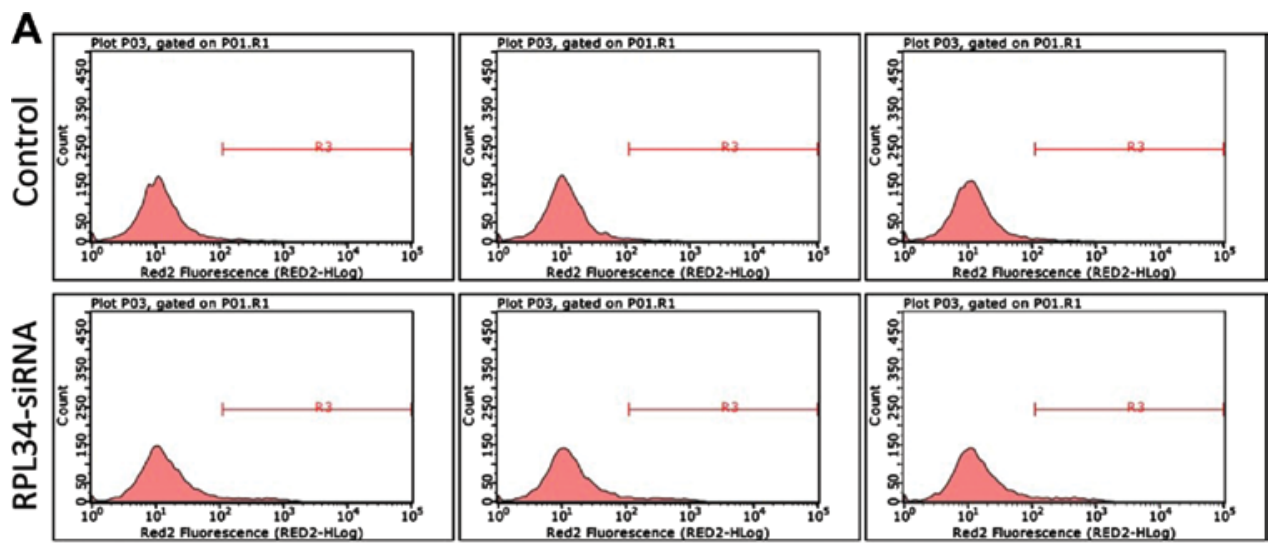

B

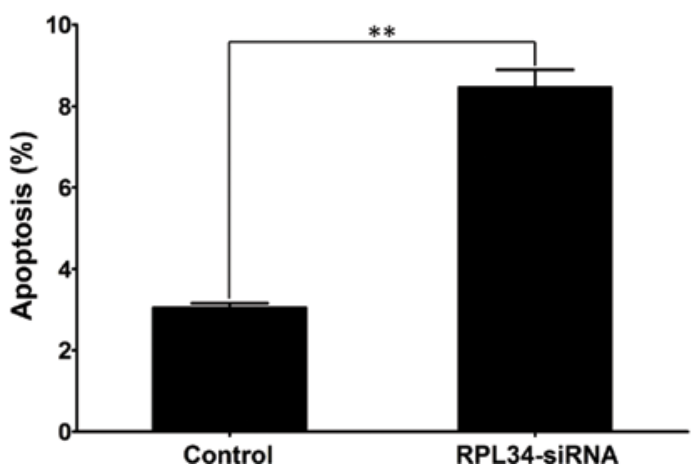

Figure 7. RPL34 knockdown increases apoptosis in the SGC-7901 cells. (A) Cell death was determined by Annexin V staining and flow cytometry. Each group is shown in triplicates. (B) Quantification of results shown in A. Note the significant increase in apoptosis in the RPL34-siRNA cultures compared with the $\mathrm{NC}\left({ }^{* *} \mathrm{p}=0.001\right)$.

by flow cytometry (Fig. 7A). As shown in Fig. 7B, cell apoptosis was significantly increased in the RPL34-siRNA group compared to the NC group (NC 3.05 $\pm 0.10 \%$ vs. RPL34-siRNA $8.46 \pm 0.43 \%, \mathrm{p}=0.001)$. These results indicate that RPL34 expression is a determinant of cell apoptosis in SGC-7901 cells.

\section{Discussion}

Gastric cancer (GC) is one of the most common cancers and the third leading cause of cancer-related death in both genders worldwide $(1,2,22)$. Gene therapy is being studied as a potential therapeutic modality for treating cancer (23). However, the development and progression of GC remain poorly understood. Therefore, it is particularly important to identify novel factors associated with gastric malignant transformation and to unravel the underlying mechanisms (24).

Ribosomal proteins (RPs), encoded by essential housekeeping RP genes, are constitutively expressed in most eukaryotic cells. While the interest in identifying human RPs comes from results indicating their involvement in human cancer $(14,25)$, most research thus far has focused on the expression and function of RPL34 in bacteria (26-28), Drosophila (26), mosquito (29) and amphioxus (30). However, RP expression and function in human GC have not yet been studied.

In the present study, we first determined the expression levels of RPL34 mRNA in four GC cell lines and found that it was expressed in all of them. Lentiviral vector is an efficient gene delivery vehicle due to its unique capability to deliver target molecules into the host cell DNA and replicate in nondividing cells (31). In order to assess RPL34 function in GC cell lines, we constructed the RPL34-siRNA lentiviral vector, which efficiently silenced RPL34 in the SGC-7901 cell line. Compared to the control-infected cells, RPL34-siRNA-treated cells showed decreased proliferation and a significant decrease in the proportion of cells in the $\mathrm{S}$ phase. A significantly increased $\mathrm{G}_{2} / \mathrm{M}$ phase population was also detected. In addition, we found that knockdown of RPL34 increased apoptosis in the SGC-7901 cells. Taken together, these results suggest that RPL34 promotes SGC-7901 cell growth. Further study is ongoing to validate the anti-apoptotic role of RPL34 in other GC cell lines.

In conclusion, in the present study we demonstrated that downregulation of RPL34 expression by RNAi in SCG-7901 cells inhibited cell proliferation and induced cell apoptosis. Therefore, knockdown of RPL34 by lentivirus-siRNA may be a candidate approach for treatment of GCs in which RPL34 is overexpressed.

\section{References}

1. Torre LA, Bray F, Siegel RL, Ferlay J, Lortet-Tieulent J and Jemal A: Global cancer statistics, 2012. CA Cancer J Clin 65: 87-108, 2015.

2. Sasako M, Inoue M, Lin JT, Khor C, Yang HK and Ohtsu A: Gastric Cancer Working Group report. Jpn J Clin Oncol 40 (Suppl 1): i28-i37, 2010

3. Catalano V, Labianca R, Beretta GD, Gatta G, de Braud F and Van Cutsem E: Gastric cancer. Crit Rev Oncol Hematol 71: 127-164, 2009. 
4. Danaei G, Vander Hoorn S, Lopez AD, Murray CJ and Ezzati M Comparative Risk Assessment collaborating group (Cancers): Causes of cancer in the world: Comparative risk assessment of nine behavioural and environmental risk factors. Lancet 366 : 1784-1793, 2005

5. Niccolai E, Taddei A, Prisco D and Amedei A: Gastric cancer and the epoch of immunotherapy approaches. World $\mathbf{J}$ Gastroenterol 21: 5778-5793, 2015.

6. Quiros RM and Bui CL: Multidisciplinary approach to esophageal and gastric cancer. Surg Clin North Am 89: 79-96, viii, 2009 .

7. Foo $\mathrm{M}$ and Leong T: Adjuvant therapy for gastric cancer: Current and future directions. World J Gastroenterol 20: 13718-13727, 2014.

8. Warner JR, Mitra G, Schwindinger WF, Studeny M and Fried HM: Saccharomyces cerevisiae coordinates accumulation of yeast ribosomal proteins by modulating mRNA splicing, translational initiation, and protein turnover. Mol Cell Biol 5: $1512-1521,1985$

9. Wool IG: The structure and function of eukaryotic ribosomes. Annu Rev Biochem 48: 719-754, 1979.

10. Roberts E, Sethi A, Montoya J, Woese CR and Luthey-Schulten Z: Molecular signatures of ribosomal evolution. Proc Natl Acad Sci USA 105: 13953-13958, 2008.

11. Ferrari S, Manfredini R, Tagliafico E, Rossi E, Donelli A, Torelli G and Torelli U: Noncoordinated expression of S6, S11, and S14 ribosomal protein genes in leukemic blast cells. Cancer Res 50: 5825-5828, 1990.

12. Fisher EM, Beer-Romero P, Brown LG, Ridley A, McNeil JA, Lawrence JB, Willard HF, Bieber FR and Page DC: Homologous ribosomal protein genes on the human $\mathrm{X}$ and $\mathrm{Y}$ chromosomes: Escape from $\mathrm{X}$ inactivation and possible implications for Turner syndrome. Cell 63: 1205-1218, 1990.

13. Chan YL, Suzuki K, Olvera J and Wool IG: Zinc finger-like motifs in rat ribosomal proteins S27 and S29. Nucleic Acids Res 21: 649-655, 1993.

14. Frigerio JM, Dagorn JC and Iovanna JL: Cloning, sequencing and expression of the L5, L21, L27a, L28, S5, S9, S10 and S29 human ribosomal protein mRNAs. Biochim Biophys Acta 1262: 64-68, 1995.

15. Strausberg RL, Feingold EA, Grouse LH, Derge JG, Klausner RD, Collins FS, Wagner L, Shenmen CM, Schuler GD, Altschul SF, et al; Mammalian Gene Collection Program Team: Generation and initial analysis of more than 15,000 full-length human and mouse cDNA sequences. Proc Natl Acad Sci USA 99: 16899-16903, 2002.

16. Aoyama Y, Chan YL and Wool IG: The primary structure of rat ribosomal protein L34. FEBS Lett 249: 119-122, 1989.

17. Tsurugi K, Collatz E, Todokoro K and Wool IG: Isolation of eukaryotic ribosomal proteins. Isolation of eukaryotic ribosomal proteins. Purification and characterization of $60 \mathrm{~S}$ ribosomal subunit proteins L3, L6, L7', L8, L10, L15, L17, L18, L19, L23', L25, L27', L28, L29, L31, L32, L34, L35, L36, L36', and L37'. J Biol Chem 252: 3961-3969, 1977.
18. Lois C, Hong EJ, Pease S, Brown EJ and Baltimore D: Germline transmission and tissue-specific expression of transgenes delivered by lentiviral vectors. Science 295: 868-872, 2002.

19. Laemmli UK: Cleavage of structural proteins during the assembly of the head of bacteriophage T4. Nature 227: 680-685, 1970.

20. Zhou Y, Su Z, Huang Y, Sun T, Chen S, Wu T, Chen G, Xie X, Li B and Du Z: The Zfx gene is expressed in human gliomas and is important in the proliferation and apoptosis of the human malignant glioma cell line U251. J Exp Clin Cancer Res 30: 114, 2011.

21. Milner AE, Levens JM and Gregory CD: Flow cytometric methods of analyzing apoptotic cells. Methods Mol Biol 80: 347-354, 1998

22. Hamashima C, Shabana M, Okamoto M, Osaki Y and Kishimoto T: Survival analysis of patients with interval cancer undergoing gastric cancer screening by endoscopy. PLoS One 10: e0126796, 2015

23. Guinn BA and Mulherkar R: International progress in cancer gene therapy. Cancer Gene Ther 15: 765-775, 2008.

24. Ludwig JA and Weinstein JN: Biomarkers in cancer staging, prognosis and treatment selection. Nat Rev Cancer 5: 845-856, 2005.

25. Pogue-Geile K, Geiser JR, Shu M, Miller C, Wool IG, Meisler AI and Pipas JM: Ribosomal protein genes are overexpressed in colorectal cancer: Isolation of a cDNA clone encoding the human S3 ribosomal protein. Mol Cell Biol 11: 3842-3849, 1991.

26. Akanuma G, Kobayashi A, Suzuki S, Kawamura F, Shiwa Y, Watanabe S, Yoshikawa H, Hanai R and Ishizuka M: Defect in the formation of $70 \mathrm{~S}$ ribosomes caused by lack of ribosomal protein L34 can be suppressed by magnesium. J Bacteriol 196: 3820-3830, 2014.

27. Panagiotidis CA, Huang SC and Canellakis ES: Relationship of the expression of the S20 and L34 ribosomal proteins to polyamine biosynthesis in Escherichia coli. Int J Biochem Cell Biol 27: 157-168, 1995.

28. Kruft V, Kapp U and Wittmann-Liebold B: Characterization and primary structure of proteins L28, L33 and L34 from Bacillus stearothermophilus ribosomes. Biochimie 73: 855-860, 1991.

29. Niu LL and Fallon AM: The ribosomal protein L34 gene from the mosquito, Aedes albopictus: Exon-intron organization, copy number, and potential regulatory elements. Insect Biochem Mol Biol 29: 1105-1117, 1999.

30. Liu L, Zhang S, Liu Z, Li H, Liu M, Wang Y and Ma L: Ribosomal proteins L34 and S29 of amphioxus Branchiostoma belcheri tsingtauense: cDNAs cloning and gene copy number. Acta Biochim Pol 52: 857-862, 2005.

31. Lever AM, Strappe PM and Zhao J: Lentiviral vectors. J Biomed Sci 11: 439-449, 2004 